\author{
PARTE 3 \\ Perspectivas e desafios para \\ a promoção do DTS no Brasil
}





\title{
Contribuições do debate sobre desenvolvimento territorial sustentável para a efetividade da gestão municipal
}

\author{
Carolina Andion*
}

\section{Resumo}

Neste artigo são avaliadas as possibilidades de aplicação do enfoque de desenvolvimento territorial sustentável no campo da gestão municipal. Num primeiro momento, a análise incide no contexto institucional e histórico da gestão municipal no Brasil. Em seguida, no exame dos principais avanços e limites do processo de federalização dos municípios, após a promulgação da Constituição de 1988. Busca-se com isso evidenciar os principais desafios que cercam o engajamento dos governos locais na promoção de novos estilos de desenvolvimento ecologicamente sustentáveis e socialmente includentes. Na sequiência, delimita-se o conceito de desenvolvimento territorial sustentável, por meio de uma incursão nas abordagens teóricas que o embasam. Na parte final, procura-se demonstrar as "possibilidades objetivas" de aplicação dessa abordagem na esfera municipal, especialmente no que se refere à concepção e implementação de planos de desenvolvimento ao mesmo tempo integrados e participativos.

Palavras-chave: Desenvolvimento territorial sustentável, políticas públicas, gestão municipal, desenvolvimento ecologicamente sustentável.

A filosofia do domínio corre o risco de cancelar a natureza e com ela, obviamente, também cancelar o ser humano. A filosofia da submissão está fundamentada na rejeição da presença do humano e nos torna impotentes. Para além das duas intenções, tais filosofias tendem ambas a destruir a nossa possibilidade de habitar a terra (ROSSI, 1998).

* Carolina Andion é doutora em Ciências Humanas pela Universidade Federal de Santa Catarina e professora do mestrado profissional em administração do Centro de Ciências da Administração e Socioeconômicas - ESAG da Universidade Estadual de Santa Catarina - UDESC. Também é pesquisadora do Centro de Pesquisa e Informação sobre a Economia Pública, Social e Cooperativa - CIRIEC Brasil. Endereço eletrônico: carol.andion@terra.com.br. 


\section{Introdução}

Ste ensaio tem como objetivo investigar as possibilidades de Eaplicação do enfoque do Desenvolvimento Territorial Sustentável (DTS) (VIEIRA, 2006; TONNEAU \& VIEIRA, 2006) em escala municipal, tendo em vista ampliar as possibilidades de planejamento e gestão na esfera dos municípios brasileiros. Para atingir esse objetivo, o caminho teórico-metodológico do artigo segue as seguintes etapas.

Primeiramente - com base numa revisão de literatura do campo da administração pública brasileira contemporânea -, trata do contexto institucional e histórico da gestão municipal no Brasil, o qual condiciona de certa forma a configuração que este fenômeno assume na atualidade. Em seguida, são identificados alguns dos principais avanços e limites do processo de federalização dos municípios, pós Constituição de 1988, buscando evidenciar, na sequiência, os impasses que devem ser suplantados e as estratégias que precisam ser fomentadas, com vistas a melhoria do desempenho técnico-administrativo e também político-institucional dos governos locais no fomento a estilos de desenvolvimento mais sustentáveis. Para delimitar o conceito de DTS aqui utilizado, é feita uma incursão nas abordagens teóricas sobre desenvolvimento territorial e desenvolvimento sustentável. A análise das contribuições e das lacunas em cada uma dessas abordagens, assim como das complementaridades existentes entre elas, acompanha-se da tentativa de compor um enfoque integrado para delimitar o escopo do conceito de DTS adotado neste texto.

Na última parte, buscamos demonstrar, com base nas considerações feitas, as "possibilidades objetivas" (GUERREIRO RAMOS, 1989) da aplicação da abordagem de DTS na esfera municipal, especialmente no que se refere à concepção e implementação de planos de desenvolvimento integrados e participativos. A construção e implementação desses planos pressupõem considerar não apenas as questões econômicas, mas também sociais, políticas e ambientais no ordenamento dos municípios. Isso implica levar em conta "novos" princípios norteadores (para além do crescimento econômico) como viabilidade, patrimonialidade e territorialidade nos processos de desenvolvimento, numa perspectiva de conexão entre as escalas municipal, estadual, federal e global (VIEIRA, 2006). 


\section{Breve contextualização da História da Administração Municipal no Brasil}

O Estado brasileiro é federalista. O Brasil é o único país no mundo que possui a coexistência de uma tripla soberania: da União, do Estado e dos Municípios. O sistema Federalista contrapõe-se ao sistema de Estado unificado presente, por exemplo, na França, no qual as regiões não possuem legislação própria, nem autonomia administrativa, pois as decisões dependem da União que é também responsável por sua criação. No Federalismo as regiões (Estados e, no caso do Brasil, municípios) possuem maior autonomia adquirindo competência legais/constitucionais e responsabilidade financeira específicas nos três poderes: executivo, legislativo e judiciário (CAMARGO, 2004).

A federalização dos municípios brasileiros é um movimento recente, introduzido pela constituição de 1988 , que expandiu a autonomia política, administrativa e fiscal dos municípios. Com isso, os municípios vão assumir funções em termos de política pública - por iniciativa própria, por adesão a algum programa proposto por outro nível de governo, ou ainda por imposição constitucional (ARRETCHE, 1999). Esse movimento de descentralização vai mudar a configuração da estrutura governamental, ampliando consideravelmente o papel dos governos locais na promoção das políticas públicas, na diminuição das desigualdades e no desenvolvimento das regiões.

Porém, é necessário ressaltar que, apesar de assumirem papéis de entes federerados apenas recentemente, o papel dos municípios na administração pública brasileira sempre foi relevante. Como ressalta Brose, a estrutura administrativa de municípios é uma herança portuguesa, que tem sua origem no Brasil Colônia. O autor explica que o município tinha então caráter urbano: "os homens de bem [aqueles que possuíam propriedades rurais] da cidade escolhiam o Conselho Municipal composto por nove vereadores, um secretário e um procurador para os assuntos administrativos" (BROSE, 2002, p.102). As câmaras municipais funcionavam como instâncias intermediárias entre as cidades e o Rei, cuidando da defesa, da manutenção da ordem e da fiscalização, permitindo uma relativa descentraliza- 
ção. As câmaras eram constituídas dos três poderes: legislativo, executivo e judiciário e eram conhecidas como Repúblicas.

Essa tradição mantém-se no período imperial, quando é instituído pela primeira vez o cargo de prefeito na província de São Paulo em 1835 (BROSE, 2002); inovação que mais tarde será ampliada às demais províncias. Já durante a primeira República, predominou a idéia de consolidar o Estado Nação e promover uma maior articulação entre o meio urbano e rural. Tal concepção vai fazer com que a prioridade seja o fortalecimento do Estado centralizado, tendência que permanece no período durante os governos de Getúlio Vargas. A constituição de 1934 estabeleceu a eletividade dos prefeitos e vereadores da câmara municipal, excluindo os prefeitos das capitais que poderiam ser nomeados. Foram também criados os primeiros impostos municipais e definida uma participação dos municípios nos impostos dos estados e da União. Com a ditadura estabelecida em 1937, os municípios perdem sua autonomia. A constituição de 1946 vai consolidar a subordinação dos municípios aos estados. A estes últimos vai caber a criação e a organização de novas municipalidades (BROSE, 2002).

Nos anos 1950, o debate sobre o papel dos municípios toma corpo e em 1952 é criado o Instituto Brasileiro de Administração Municipal (IBAM). Foi também nesta época que se criou o Fundo de Participação dos Municípios que vigora até hoje (MELLO, 2001). Com isso, defende-se a idéia, ao longo das décadas 1950 e 1960, da modernização das prefeituras, tendo como inspiração o movimento da progressive public administration americano. O objetivo era implantar uma administração burocrática e profissionalizada, imune às influências patrimoniais. Esse movimento inicia-se com Getúlio Vargas, com a primeira Reforma Administrativa, ainda nos anos 1930 e mantém-se na época do regime militar. Com a reforma administrativa introduzida em 1967, a idéia era ampliar as bases do Estado, por meio da administração indireta, esterelizada pela sua separação da política (GAETANI, 1999). Forma-se, assim, uma "tecnoburocracia insulada" que se desenvolve e toma as decisões à mercê dos interesses políticos. Tal insulamento visava reduzir o escopo da arena em que demandas e interesses pessoais exerciam influência (NUNES, 1997). Porém, como afirma Brose (2002), as 
reformas realizadas durante o período militar pouco atingiram a esfera municipal e concentraram-se no fortalecimento de um Estado interventor e centralizado. De fato, pode-se afirmar que, principalmente no meio rural, se mantém até hoje quase inalterada a influência de padrões privados (mandonismo, coronelismo, autoritarismo e nepotismo) na esfera pública municipal. Tais padrões ainda estão fortemente presentes na nossa cultura política (Da MATTA, 1991 e NUNES, 1997).

Percebe-se que o binômio centralização/descentralização é um tema central na trajetória da administração pública brasileira. A preocupação com a efetividade da administração municipal não é recente. Como abordado brevemente acima, a questão do papel dos municípios na administração pública é algo que vem sendo discutido e praticado desde a origem do Estado no país. O que muda atualmente é que os municípios ganharam maior autonomia política, administrativa, legislativa e financeira. Os municípios não estão mais subordinados ao Estado e à união, apesar de ainda dependerem financeiramente destes, na maioria dos casos. Sua criação depende da vontade da população local (por meio dos plebiscitos), embora sujeita à regulamentação. Todo esse processo vai transformar substancialmente a estrutura político-institucional do país e merece que nos debrucemos sobre a atual constituição da gestão municipal, seus avanços e limites.

\section{Avanços e limites do processo de municipalização}

No Brasil existem 5.565 municípios constituídos por um poder executivo (Prefeito) e um poder legislativo (Câmara Municipal, constituída de vereadores), ambos eleitos pelo voto popular. Como destaca Mello (2001), as competências dos municípios foram, desde o Império, definidas vagamente, o que favorece a concorrência entre os níveis de governo e também estimula lacunas na prestação dos serviços públicos. A Constituição menciona como serviços municipais: organizar e prestar, diretamente ou sob regime de concessão ou de permissão, os serviços públicos de interesse local, inclusive o transporte coletivo urbano, que terá caráter essencial. Porém, outros serviços municipais, além do transporte, não são especificados. 
Vários são os estudos que buscam, nos últimos anos, uma maior compreensão sobre os efeitos do processo de municipalização no Brasil, após 20 anos de sua implantação (ARRETCHE, 1999; FARAH, 2000; FARAH e BARBOZA 2001; BROSE, 2002; TOMIO, 2002; CAMARGO, 2004; FAURÉ, 2005). Pode-se perceber nos últimos anos uma expansão vertiginosa do número de municípios no Brasil, acelerada pela Constituição de 1988. Como cita Tomio (2002) entre 1988 e 2000 , foram criados 1.438 novos municípios, o que corresponde a $25 \%$ do total de municípios existentes atualmente no Brasil. Essa ampliação tem gerado alguns efeitos positivos e negativos apontados pelos autores em diferentes dimensões da administração pública e que são sintetizados a seguir. Dentre os avanços apontados pode-se destacar:

- O reforço na descentralização das políticas públicas, especialmente as sociais, que antes eram centradas apenas na união e nos estados federados, promovendo uma importante mudança institucional no aparato governamental. Segundo Arretche (1999) instâncias colegiadas estaduais e municipais eram responsáveis, em 1997, pela alocação da totalidade dos recursos do FGTS, assim como pela gestão dos recursos destinados a merenda escolar e $69 \%$ das consultas médicas eram realizadas através de prestadoras estaduais ou municipais, sendo que dessas $54 \%$ eram prestadas pelos municípios.

- A ênfase no local tem permitido a concretização de experiências inovadoras de governança nos meios urbanos e rural (FARAH \& BARBOZA, 2001). Dentre as experiências pode-se destacar o orçamento participativo, a criação de consórcios intermunicipais ou ainda a formação de fóruns e câmaras intersetorais para promoção do desenvolvimento local.

- A ampliação da participação da sociedade civil na esfera pública, por meio da promoção de uma nova articulação entre Estado, sociedade civil e setor privado, visando à garantia dos serviços públicos (FARAH, 2000). Com a ênfase no local há uma maior aproximação das entidades prestadoras de serviços públicos e os cidadãosusuários, fazendo com que se tenha maior possibilidade de atendimento a demandas não massificadas, maior transparência e ampliação do controle social. 
- Aumento da participação dos municípios na repartição dos recursos fiscais, diminuindo a concentração destes na esfera estadual e federal, embora a maior parte dos recursos públicos ainda esteja concentrada nessas duas esferas.

- Observando apenas esses fatores, pode-se inferir que o processo de municipalização tenha gerado um grande avanço na estruturação do Estado, na própria gestão pública e na promoção do desenvolvimento, já que as iniciativas municipais são mais realistas economicamente, mais pertinentes e mais orientadas às necessidades da população local. Porém, observando os resultados reais da descentralização, pode-se perceber que este processo tem apresentado inúmeros entraves à sua efetiva implementação. Dentre eles destacam-se:

- Uma multiplicação exponencial do número de municípios que são criados sem a mínima condição de sustentabilidade no longo prazo, muitas vezes com base em critérios políticos. Como demonstra Camargo (2004), 80\% dos municípios brasileiros não produzem nenhum recurso orçamentário próprio e $60 \%$ deles têm pelo menos $85 \%$ do seu orçamento proveniente de transferências do Estado e da União. Outro fator importante na composição do fluxo fiscal desses municípios são as aposentadorias. $O$ resultado é uma alta concentração populacional nas cidades urbanas $(80 \%$ da população brasileira vive nas 100 maiores cidades) e uma grande quantidade de municípios muito pequenos carentes de infra-estrutura e isolados em termos de mercado.

- Uma grande fragilidade das esferas institucionais de governança nos municípios. A maioria dos conselhos são formados por indicação dos prefeitos e não dispõem de capacidade técnica, administrativa e financeira para exercer a sua função de reguladores das políticas públicas (FAURÉ, 2005). Esse quadro é ainda mais crítico nas zonas rurais que compreendem mais de $80 \%$ dos 5.565 municípios brasileiros. A título de ilustração, apenas $41 \%$ dos municípios brasileiros possuem na atualidade um plano municipal de educação (CNPq, 2008). Essa mesma situação repete-se nas outras áreas. Os planos setoriais municipais, na maioria dos casos, não só representam meras formalidades - com o intuito principal de responder às exigências impostas pelos órgãos go- 
vernamentais superiores - como não apresentam caráter inovador no sentido de estabelecer interrelações entre os diferentes setores socioeconômicos e parcerias entre municípios de uma mesma zona geográfica.

- Ainda prevalece uma falta de articulação entre níveis de governo, entre os poderes e entre os setores da administração pública no âmbito local. Faltam espaços de articulação e canais de comunicação mais eficazes entre os níveis governamentais e, além disso, permanece uma indefinição em termos de papéis e responsabilidades de cada nível. As iniciativas multiplicam-se, mas sem uma devida articulação entre elas. Como explica Camargo (2004) a federalização dos municípios levou a uma maior complexificação das relações intergovenamentais (federalismo anárquico), tendo em vista a triangulação entre união, estados e municípios. Isso dificulta os acordos, sobretudo considerando a influência de aspectos políticos partidários.

- Falta uma continuidade administrativa e ainda há uma forte influência dos padrões patrimonialista (mandonismo, clientelismo, autoritarismo) na esfera municipal. A descontinuidade das políticas e a influência de padrões privados na esfera pública é um dos graves problemas que dificultam a efetividade da gestão pública municipal.

- Natureza assimétrica do federalismo brasileiro, configurando fortes desigualdades espaciais e regionais. Segundo Camargo (2004), a região Sudeste concentra $65 \%$ da renda nacional. O resultado, como mostram Pochmann e Amorim (2003), é a existência alguns "acampamentos" de inclusão social em meio a uma "selva" de exclusão. 49\% dos municípios brasileiros têm elevado grau de desigualdade na distribuição da renda e encontram-se, sobretudo, nas regiões Norte e Nordeste e somente 10,3\% conta com estrutura ocupacional marcada pela formalidade

Pode-se, então, concluir que o processo de municipalização não pode ser interpretado como um remédio para todos os males da administração pública ou como uma fórmula mágica para descentralizar o desenvolvimento. As mudanças promovidas por esse processo produziram alguns avanços institucionais, porém geraram também novos problemas que precisam ser equacionados. Pode-se 
concluir que a descentralização (entendida como transferência de responsabilidades e autoridade para os níveis inferiores de governo e também para a sociedade civil) não se produz automaticamente, por "decreto"; é necessário a construção progressiva de novos arranjos institucionais e sua prática, gerando novos aprendizados em termos de exercício democrático. Como observado, pela breve exposição histórica feita no item 1 , a descentralização no Brasil tem sido comandada de cima para baixo e a divisão territorial tem ocorrido, historicamente, de forma imposta pelo Estado, sem incentivos nem dinâmicas de colaboração que possam fazer avançar o processo. Neste sentido, coloca-se a importância de repensar esse modelo e implementar novas estratégias que permitam otimizar a descentralização dos processos de desenvolvimento, mantendo a capacidade de regulação do Estado. Tais aspectos serão abordados a seguir.

\section{Em direção a uma maior efetividade na Adminis- tração Municipal: rumo ao Desenvolvimento Territorial Sustentável (DTS)}

A superação dos limites acima expostos implica em mudanças de cunho técnico-administrativo e, sobretudo, políticas, as quais só poderão concretizar-se no longo prazo. Sem a pretensão de apresentar resposta a todos os dilemas levantados - cuja solução depende de transformações nas diferentes dimensões da administração pública - gostaríamos de chamar a atenção neste texto para as possibilidades objetivas da aplicação do enfoque do Desenvolvimento Territorial Sustentável (DTS) na gestão municipal no caso brasileiro. A emergência da noção de DTS, mais do que trazer à tona um novo "conceito" ou "sentido", exprime a complexificação do debate epistemológico no campo dos estudos sobre desenvolvimento. Trata-se de produzir conexões entre a abordagem atual sobre desenvolvimento territorial e a tradição do debate no campo do desenvolvimento e ecologia e, mais particularmente, com o enfoque do ecodesenvolvimento (SACHS, 1980, 1986, 1997, 2000 e VIEIRA, 2001 e 2006). A seguir tratamos brevemente desses dois campos para em seguida relacioná-los, tendo como foco a sua aplicação no âmbito municipal. 


\subsection{A abordagem do desenvolvimento territorial}

Para alguns autores como Beduschi Filho e Abramovay (2004) a abordagem territorial pode ser uma alternativa viável para superar alguns dos limites do processo de municipalização. $\mathrm{O}$ enfoque territorial implica a transição de uma lógica burocrática e de "balcão" na promoção do desenvolvimento e na gestão das políticas públicas, para uma lógica baseada em projetos e que valorize as vocações e os recursos específicos do territorio ${ }^{1}$. A idéia é estimular processos colaborativos entre esferas pública e privada no planejamento e implantação de políticas públicas voltadas para o desenvolvimento, levando em conta as particularidades históricas, culturais e políticas de cada região.

A corrente do desenvolvimento territorial é recente e composta por estudos no domínio da economia, sobretudo pelos trabalhos da escola de Grenoble na França (PECQUEUR, 2005, 2006), e por novos campos disciplinares, tais como a sociologia econômica (FONTAN, KLEIN e LÉVESQUE, 2003) e a geografia socioeconômica (BENKO \& LIPIETZ, 2000). Além de considerar os "novos poderes locais" emergentes na cena do desenvolvimento, a abordagem territorial permite qualificar melhor esta cena, por meio da noção de território. O lugar do espaço nos processos de desenvolvimento nesta leitura redefine-se, em contraposição à visão da economia espacial ou regional clássica. O território é interpretado não como uma estrutura estática, definida por limites geográficos ou administrativos; ele passa a ser definido como um verdadeiro campo de forças, cuja dinâmica é particular em cada caso analisado.

O território torna-se, assim, o palco central das dinâmicas de desenvolvimento: "uma unidade que dispõe de recursos ativos

1 A noção de recurso específico refere-se a uma potencialidade, quer dizer, vai além dos recursos diretamente presentes e disponíveis para serem usados numa atividade produtiva. Segundo Pecqueur e Colletis (1993), há uma diferença entre recurso e ativo. $\mathrm{O}$ ativo é um fator em atividade, quer dizer, valorizado pelo mercado. $O$ recurso constitui uma reserva, um potencial latente, ou até virtual que pode se transformar em ativo se as condições de produção ou de criação tecnológica lhe permitirem. O que interessa na análise, segundo esses autores, é o esforço do território para manifestar sua identidade, quer dizer valorizar a especificidade de seus recursos, transformando-os em ativos específicos. 
(no sentido da contabilidade), específicos e não transferíveis de uma região para uma outra" (CARRIÈRE, 2004, p.6). Por esse motivo, a recomposição territorial não se faz jamais de forma idêntica em todos os lugares e as estratégias de desenvolvimento não são universais, nem seguem um modelo definido; "elas convidam cada localidade ou região, que enfrenta uma situação de declínio, a inventar o seu próprio modelo de reconversão" (FONTAN, KLEIN \& LÉVESQUE, p.6).

Pecqueur (2006) argumenta que o fato territorial aparece sob múltiplas formas, em função dos contextos sociais, culturais e econômicos nos quais ele manifesta-se. Da mesma maneira, a noção de território pode reenviar também a múltiplos significados. Este mesmo autor (2005) estabelece uma diferenciação entre as noções de território dado e território construído. O território dado é definido por ele como uma porção de espaço (na maioria das vezes um recorte administrativo) constituído a priori. Neste caso, não se busca analisar a sua gênese e as suas condições de elaboração. Já o território construído é resultado de um processo de mobilização dos atores locais. Ele não está definido, ele é constatado a posteriori.

Já Deffontaines, Marcelpoil e Moquay (2001, p.49), apresentam uma definição mais ampla de território: "trata-se do teatro ou da cena onde se desenrola uma dinâmica socio-espacial; ele reenvia a um processo em curso, onde existe uma relação entre o social e o espacial". Nesta definição, tornam-se concebíveis num mesmo espaço geográfico, múltiplos "processos de territorialização" e não apenas aquele definido por uma dinâmica produtiva (priorizada na definição de Pecqueur). Para exemplificar esses processos, os autores citados referem-se aos setores (relacionados às atividades setorializadas que cada ator exerce e vive); aos recortes administrativos (caracterizados pelos espaços de decisão e de interação das instâncias administrativas); ou ainda, aos projetos de desenvolvimento (caracterizados por uma intervenção numa problemática específica).

Gumuchian et al. (2003) complementam essa leitura, fazendo uma diferenciação entre as múltiplas territorialidades presentes em todo espaço geográfico e a formação dos territórios. Segundo esses autores, as múltiplas territorialidades refletem as estratégias 
(individuais ou coletivas) colocadas em prática pelos atores sociais, buscando apropriar-se e transformar um contexto territorial (espacial, cultural e temporal) específico. Estas territorialidades entram em interação umas com as outras ou podem ficar isoladas, desconhecidas. Porém, essa infinidade de territorialidades não dá origem a uma infinidade de territórios. Para Gumuchian et al. (2003, p.91) a emergência de um território implica algumas condições:

uma forma organizada de ação coletiva; uma estruturação entre as posições dos atores, para que o território tenha uma certa permanência; um reconhecimento do fato territorial e/ou da ação que ele induz, ou seja, uma institucionalização; e uma representação ordenada do real espacial, à partir da qual a ação vai se inscrever no espaço.

Porém, é importante considerar que essas condições podem variar, dependendo do espaço analisado e do caráter de institucionalização do processo de desenvolvimento. A ação coletiva pode ser menos organizada e estruturada, por exemplo, no caso dos processos de desenvolvimento espontâneo, que são mais flexíveis, informais e difusos, do que nos processos induzidos, onde há uma certa harmonização de demandas e uma arbitragem clara (DEFFONTAINES, MARCELPOIL \& MOQUAY, 2001). Nos dois casos, porém, a tensão permanente entre a cooperação e o conflito entre os atores e grupos sociais constitui um traço característico.

Outro aspecto a salientar é que, na abordagem territorial, a focalização nas especificidades do local não reduz a importância do estabelecimento de relações com o exterior. Tratando este aspecto, Arocena (2004) mostra que a idéia do local é sempre relativa, quer dizer, refere-se sempre a um contexto global. Ele critica a visão "comunitarista" algumas vezes expressa nos estudos sobre o desenvolvimento local, levantando o risco de se cair em análises puramente ideológicas que descrevem o território como o remédio a todos os males ou ainda como uma espécie de gueto preservado frente às influências das sociedades urbanas. Essa visão nostálgica, segundo o autor, deve ser substituída por uma concepção complexa que tome distância tanto de leituras globalizantes, quanto reducionistas.

Enfim, pode-se inferir que o território não está em todo lugar, nem todo lugar é um território (COURLET \& FERGUÈNE, 2004). 
Com base nos autores supramencionados, observa-se que em todo espaço existem múltiplas territorialidades, porém isso não implica o mesmo número de territórios. Nesta concepção, a formação de um território não é um processo natural, nem pode ser conduzido de cima para baixo. Exige uma organização/cooperação dos atores locais, visando mobilizar e colocar em valor os recursos territoriais, por meio de estratégias específicas, tanto no nível organizacional, quanto institucional. Algumas das estratégias de fortalecimento da dinâmica territorial, citadas pelos autores são as seguintes:

- O fortalecimento das redes formais e informais que se formam num território ao longo do tempo;

- A ênfase numa economia plural formada por diferentes enclaves produtivos e modos de regulação econômica (redistribuição, troca mercantil e reciprocidade) que se estruturam na esfera mercantil e não mercantil;

- A valorização da memória, da cultura, da identidade, dos recursos naturais e das instituições locais, como elementos não transferíveis e não mercantis que podem fornecer um importante diferencial em termos de desenvolvimento;

- A promoção da inovação, tanto técnica como das formas de organização do trabalho e das relações produção, que é concebida como instrumento de adaptação e reação às mudanças globais;

- A disseminação dos aprendizados e inovações, bem como a criação de "barreiras de entrada" que permitam discriminar entre o sistema e seu exterior, pois como destaca Pecqueur (2005, p.312): "se um sistema pode ser facilmente invadido pelos postulantes externos, o efeito diferenciador se enfraquece e a vantagem comparativa diminui para os membros do sistema";

- A concepção de uma "cesta de bens e serviços" territorializados, que não se restringe a uma simples listagem de bens e serviços privados de caráter comercial, mas resulta de uma associação positiva de bens e serviços públicos e privados, o que pressupõe a existência de uma estratégia pública que pode variar de um território para outro; 
- E finalmente, a capacidade dos atores locais de produzir as condições e as regras que, considerando o quadro institucional existente, permitam perenizar os processos de desenvolvimento.

A abordagem do desenvolvimento territorial pode apresentar importantes pistas para superação de alguns dos limites da municipalização como o excesso de localismo; a influência de práticas patrimonialistas; a falta de recursos e habilidades técnicas nos municípios pequenos; as fortes desigualdades intraregionais, entre outros. Por meio de estratégias específicas - como o estímulo à colaboração intermunicipal; à transversalidade entre mundo rural e urbano, entre as diferentes atividades e grupos estratégicos presentes no território e a articulação entre os diferentes níveis governamentais - o enfoque territorial pode ajudar a superar o dilema descentralização/centralização presente na administração pública desde os seus primórdios.

Porém, um dos principais limites do enfoque territorial consiste na desconsideração da interface entre desenvolvimento \& ecologia (VIEIRA, CAZELLA e CERDAN, 2006; VIEIRA, 2006 e ANDION, SERVA \& LÉVESQUE, 2006). De fato, a construção do conceito de desenvolvimento territorial vem sendo realizada sem levar em conta os efeitos da crise socioambiental planetária. Aí reside uma dos principais lacunas da abordagem territorial e se encontra o espaço de complementaridade com a noção de sustentabilidade que vem se estruturando há algumas décadas no campo de estudos que relaciona desenvolvimento \& meio-ambiente.

\subsection{Integrando a dimensão ambiental no enfoque territorial: uma incursão no debate sobre desenvolvimento e meio-ambiente}

Apesar da evidente interdependência entre os processos de desenvolvimento e as dinâmicas ambientais, a relação entre meioambiente e desenvolvimento emerge nos debates científicos e políticos internacionais apenas a partir do final da década de 1960, em função de pelo menos três movimentos inter-relacionados (ANDION, 
2007). Primeiramente, destacam-se as discussões que ocorreram no quadro das grandes organizações internacionais, especialmente a Organização das Nações Unidas (ONU). Essas discussões, por sua vez, foram influenciadas e influenciaram o campo acadêmico, de onde emergiram abordagens teóricas tratando da dimensão ecológica do desenvolvimento, como as abordagens do ecodesenvolvimento, do desenvolvimento sustentável e do desenvolvimento durável, entre outras. Além disso, o movimento ambientalista e a sua institucionalização desempenharam também um papel importante na estruturação do debate sobre o meio-ambiente e o desenvolvimento.

Não nos concentraremos aqui no detalhamento da trajetória histórica da construção do conceito de sustentabilidade ${ }^{2}$, o que fugiria ao escopo desse texto. Porém - a partir de uma análise de conjunto das diferentes abordagens sobre o tema sem perder de vista a sua historicidade - pode-se afirmar que o campo teórico de interface entre desenvolvimento e meio-ambiente é pluralista e vasto, caracterizado por uma orientação interdisciplinar e pela interação entre teoria e prática; entre técnica e política. Mais especificamente, percebe-se atualmente a coexistência de diferentes definições de sustentabilidade. Não há, portanto, uma definição única, nem hegemônica de "desenvolvimento sustentável”. Sinteticamente, pode-se identificar pelo menos três "grandes" orientações no debate, as quais refletem visões distintas de aspectos como o meio-ambiente, a relação ser humano/natureza, a relação entre desenvolvimento e crescimento, entre outros:

- A orientação de limitação ao crescimento econômico, representada pelas propostas do Clube de Roma (MEADOWS et al., 1972) e da deep ecology ${ }^{3}$;

2 Para um aprofundamento nessa trajetória ver Vieira (2006) e Andion (2007).

3 A Deep Ecology é uma expressão criada pelo filósofo Arne Naess, em 1972, o qual vai desenvolver posteriormente uma corrente de pensamento na filosofia, a ecosofia. Esta corrente considera o ser humano como parte integral do seu meio-ambiente e rejeita a idéia da existência de uma hierarquia entre os seres vivos. Segundo Naess (1990), o direito de todos os seres de viver é um direito universal. Neste raciocínio, nenhuma espécie de ser vivo, nem mesmo o ser humano, tem mais direito de viver e de se desenvolver do que as demais. 
- a orientação do "ser-humano-no-ecossistema", representada pelas abordagens do ecodesenvolvimento (SACHS, 1980, 1986, 1997, 2000 e VIEIRA, 2001), do desenvolvimento durável (PASSET, 1979, 1992), complementada pelos estudos mais recentes no campo das ciências ambientais (VAILLANCOURT, 1995, JOLLIVET \& PAVÉ, 1997, BERKES; FOLKES, 1998, BERKES; COLDING \& FOLKE, 2003);

- a orientação do crescimento econômico sustentável, representada de forma extrema pelas propostas dos autores neoclássicos (PEZZEY, 1989) e de forma mais branda pela escola de Londres (PEARCE, MARKANDYA \& BARBIER, 1989) e pelo conceito de desenvolvimento sustentável divulgado pelo relatório Bruntland.

No Quadro 1, a seguir, são comparados os principais argumentos dessas três orientações, situando-as num continuum que oscila de uma visão biocêntrica (sustentabilidade muito forte), a uma visão antropocêntrica (sustentabilidade fraca) da relação entre meio-ambiente e desenvolvimento.

Quando nos referimos ao conceito de sustentabilidade neste texto, estamos tratando da orientação do "ser-humano-noecossistema”, referida acima. Nessa orientação, o desenvolvimento sustentável é definido como um processo que se busca alcançar no longo prazo e cujas consequiências não são totalmente previsíveis (HOLLING, BERKES \& FOLKES, 1998). Essa definição baseia-se numa noção de sustentabilidade forte, que considera a solidariedade entre as gerações e que atenta para as três dimensões interdependentes do desenvolvimento: a dimensão ecológica, a dimensão social e a dimensão econômica. Em particular, a abordagem do ecodesenvolvimento detalha com mais clareza o significado que será aqui atribuído ao conceito de desenvolvimento sustentável.

Para Sachs (1980) e Vieira (2001), o ecodesenvolvimento é entendido como um estilo de desenvolvimento que tem por base alguns princípios. 


\section{Quadro 1 - Orientações teóricas no debate sobre a sustentabilidade}

\section{Concepção biocêntrica}

\section{Concepção co-evolutiva}

\section{Concepção antropocêntrica}

\begin{tabular}{|c|c|c|c|}
\hline $\begin{array}{l}\text { Orientações/ } \\
\text { Variáveis }\end{array}$ & $\begin{array}{l}\text { Limitação do Cresci- } \\
\text { mento Econômico }\end{array}$ & $\begin{array}{l}\text { Perspectiva do } \\
\text { "ser humano-no- } \\
\text { ecossistema" }\end{array}$ & $\begin{array}{l}\text { Crescimento Econômi- } \\
\text { co Sustentável }\end{array}$ \\
\hline Meio Ambiente & $\begin{array}{l}\text { Considera prioritariamen- } \\
\text { te os meios naturais, con- } \\
\text { trapondo-os ao sistemas } \\
\text { socioculturais, a partir de } \\
\text { uma visão mais bio-física } \\
\text { do ecossistema. A natu- } \\
\text { reza assume um valor } \\
\text { que lhe é próprio e não } \\
\text { pode ser substituído. }\end{array}$ & $\begin{array}{l}\text { Considera o conjunto de } \\
\text { meios naturais ou artificia- } \\
\text { lizados da ecosfera onde o } \\
\text { homem se instalou e que } \\
\text { ele explora e administra, } \\
\text { bem como o conjunto dos } \\
\text { meios não submetidos à } \\
\text { ação antrópica e que são } \\
\text { necessários à sua sobre- } \\
\text { vivência. A dicotomia natu- } \\
\text { reza cultura é superada por } \\
\text { uma visão simbiótica entre } \\
\text { ser humano e natureza. }\end{array}$ & $\begin{array}{l}\text { A natureza é vista como } \\
\text { uma fonte de recursos, } \\
\text { que deve ser utilizada } \\
\text { com responsabilidade } \\
\text { pelo ser humano, o qual } \\
\text { deve responder pelos } \\
\text { custos de suas ações } \\
\text { (política compensatória). } \\
\text { Há uma capacidade } \\
\text { quase infinita de substi- } \\
\text { tuição dos valores natu- } \\
\text { rais e monetários. } \\
\text { O foco maior são as } \\
\text { conseqüências e não as } \\
\text { causas das problemáti- } \\
\text { cas ambientais. }\end{array}$ \\
\hline $\begin{array}{l}\text { Relação entre } \\
\text { ser humano e } \\
\text { natureza }\end{array}$ & $\begin{array}{l}\text { O ser humano deve se } \\
\text { integrar e submeter à } \\
\text { lógica dos sistemas na- } \\
\text { turais, pois depende da } \\
\text { natureza. }\end{array}$ & $\begin{array}{l}\text { Relação simbiótica no sen- } \\
\text { tido forte do termo. Abando- } \\
\text { na o falso critério de artifi- } \\
\text { cialidade e de naturalidade } \\
\text { e mais do que postular um } \\
\text { impossível status quo entre } \\
\text { ser humano e natureza, } \\
\text { busca formas socialmen- } \\
\text { te úteis e ecologicamente } \\
\text { prudentes de valorizar os } \\
\text { recursos naturais. }\end{array}$ & $\begin{array}{l}\text { O homem está acima } \\
\text { da natureza, ele toma } \\
\text { posse e exerce domínio } \\
\text { sobre ela, por meio do } \\
\text { trabalho e da tecnologia, } \\
\text { visando atender as suas } \\
\text { necessidades. }\end{array}$ \\
\hline $\begin{array}{l}\text { Relação entre } \\
\text { desenvolvimen- } \\
\text { to e cresci- } \\
\text { mento }\end{array}$ & $\begin{array}{l}\text { Defende a busca de um } \\
\text { estado de equilíbrio eco- } \\
\text { nômico e ecológico (ste- } \\
\text { ady state) que pressu- } \\
\text { põe necessariamente a } \\
\text { limitação do crescimento } \\
\text { econômico e populacio- } \\
\text { nal e, no limite, o cresci- } \\
\text { mento zero. }\end{array}$ & $\begin{array}{l}\text { A questão não é parar o } \\
\text { crescimento, mas buscar } \\
\text { novas modalidades de de- } \\
\text { senvolvimento que possam } \\
\text { adaptar, de forma ecologi- } \\
\text { camente prudente, o meio } \\
\text { ambiente às necessida- } \\
\text { des do homem. Levanta a } \\
\text { necessidade de repensar } \\
\text { as formas tradicionais de } \\
\text { crescimento, questionando } \\
\text { a qualidade da relação en- } \\
\text { tre o sistema sociocultural } \\
\text { e o meio-ambiente. }\end{array}$ & $\begin{array}{l}\text { O crescimento econômi- } \\
\text { co -capaz de promover } \\
\text { o desenvolvimento de } \\
\text { tecnologias adaptadas - } \\
\text { é um pré-requisito para } \\
\text { atingir a sustentabilida- } \\
\text { de. Considera que a eco- } \\
\text { nomia internacional deve } \\
\text { acelerar o crescimento } \\
\text { mundial, respeitando as } \\
\text { limitações ecológicas, } \\
\text { mas não discute o estilo } \\
\text { de desenvolvimento que } \\
\text { deve ser promovido. }\end{array}$ \\
\hline
\end{tabular}




\begin{tabular}{|c|c|c|c|}
\hline $\begin{array}{l}\text { Relação entre a } \\
\text { tecnologia e o } \\
\text { meio ambiente }\end{array}$ & $\begin{array}{l}\text { Apenas o uso da tecnolo- } \\
\text { gia não tem um impacto } \\
\text { nos problemas essen- } \\
\text { ciais e não poderá evitar } \\
\text { o colapso. Entretanto, o } \\
\text { uso de tecnologias lim- } \\
\text { pas e leves é necessário } \\
\text { e bem vindo no estado de } \\
\text { equilíbrio, tais como: reci- } \\
\text { clagem, energias limpas, } \\
\text { avanço nos métodos con- } \\
\text { traceptivos, etc. }\end{array}$ & $\begin{array}{l}\text { Enfatiza o uso de tecno- } \\
\text { logias apropriadas e que } \\
\text { produzam poucos dejetos, } \\
\text { no lugar da escalada atu- } \\
\text { al de produção-poluição e } \\
\text { despoluição. Isso implica a } \\
\text { concepção de sistemas de } \\
\text { produção que aproveitem } \\
\text { às potencialidades locais e } \\
\text { que favoreçam a busca de } \\
\text { complementaridades das } \\
\text { varias alternativas de dina- } \\
\text { mização socioeconômica. }\end{array}$ & $\begin{array}{l}\text { Enfatiza a importância } \\
\text { do uso de tecnologias } \\
\text { limpas e adaptadas } \\
\text { que possam contribuir } \\
\text { para concretizar o ciclo } \\
\text { do desenvolvimento } \\
\text { sustentável. }\end{array}$ \\
\hline Economia & $\begin{array}{l}\text { Negligencia a dimensão } \\
\text { econômica, enfatizando } \\
\text { os aspectos para além do } \\
\text { econômico (degradação } \\
\text { ambiental). }\end{array}$ & $\begin{array}{l}\text { Focaliza a economia plural, } \\
\text { formada por diferentes for- } \\
\text { mas de regulação e agen- } \\
\text { tes tanto no espaço local, } \\
\text { como global (economia } \\
\text { formal e informal, mercantil } \\
\text { e não mercantil). Trabalha } \\
\text { com um novo conceito de } \\
\text { eficiência econômica, ba- } \\
\text { seado na idéia de ecoefici- } \\
\text { ência. }\end{array}$ & $\begin{array}{l}\text { Privilegia a esfera } \\
\text { da economia formal, } \\
\text { formada pelas trocas } \\
\text { mercantis. }\end{array}$ \\
\hline
\end{tabular}

Fonte: Elaborado pela autora a partir das referências citadas na página anterior.

- A prioridade do desenvolvimento recai na busca de satisfação das necessidades sociais básicas e na promoção da equiiidade e não apenas no crescimento econômico.

- Pressupõe um outro padrão de relação sociedade-natureza. Sugere o aprendizado de um padrão pautado pela relação da simbiose co-evolutiva com a natureza.

- Considera indispensável a participação da sociedade civil organizada e o fomento à autonomia das comunidades locais envolvidas (self-reliance). Atribui-se aos atores locais a capacidade de co-gerenciar de forma prudente a base de recursos disponíveis.

- Considera a viabilidade econômica, mas re-significa a economia, ou seja, efetua sua inscrição nos fenômenos sociais e ambientais (ANDION, SERVA \& LÉVESQUE, 2006). Isso significa rever as formas de consumo, considerando diferentes lógicas de regulação econômica e de uso do tempo nas sociedades. Além disso, estimula a revisão dos padrões usuais de oferta de bens e serviços (formas de produção), envolvendo a gestão da tecnologia, 
o abastecimento de matérias primas, o suprimento energético, a organização espacial das atividades produtivas e a política de gestão de recursos naturais.

- Levam em conta as perspectivas sincrônica e diacrônica do desenvolvimento, contemplando a necessidade de se garantir a transmissão intergeracional do patrimônio natural e cultural da humanidade.

Finalmente, a orientação aqui adotada é não somente heurística, mas também voltada para a ação (JOLLIVET \& PAVÉ, 1997). O debate atual sobre o desenvolvimento sustentável mostra que os desafios do presente estão situados não apenas na esfera da produção teórica, mas, principalmente, no campo da prática (ANDION, SERVA \& LÉVESQUE). O relatório do PNUMA já confirmava essa constatação em 1997, com a seguinte avaliação sobre a cúpula Rio + 5:

Cinco anos após a Rio-92, a comunidade internacional convocou uma nova cúpula chamada Rio +5 para rever os compromissos empreendidos no Rio de Janeiro em 1992. Durante o encontro, realizado em Nova York, houve uma preocupação em relação à lenta implementação da Agenda 21. A conclusão geral foi a de que, embora um certo progresso houvesse sido feito em relação ao desenvolvimento sustentável, várias das metas da Agenda 21 ainda estão longe de se concretizar (PNUMA, IBAMA \& UMA, 2004).

Neste contexto, coloca-se a importância de um enfoque "de baixo para cima”, que focalize experiências concretas de promoção novos estilos de desenvolvimento. Neste sentido, o município pode ser uma escala interessante para se pensar a noção de "território" e a sua conexão com a "sustentabilidade". O enfoque do DTS abre então novas vias que podem ser exploradas para repensar o planejamento e a gestão pública municipais.

Trata-se de uma nova abordagem analítica em termos de desenvolvimento que busca integrar noções que até então eram interpretadas a partir de uma visão dual como: local/global; objetivo/ subjetivo; sistemas sociais/ecossitemas; natureza/cultura (ANDION, 2007). A sustentabilidade de um território reenvia a princípios universais (que visam responder a uma crise ambiental global), mas também, pressupõe articulações e acordos específicos entre os atores 
locais que precisam se apropriar das dinâmicas de desenvolvimento. Por outro lado, devem ser considerados tanto aspectos objetivos, quanto subjetivos da problemática socioambiental, além da relação de interdependência entre sistemas sociais e ecossistemas, transpondo assim uma visão dicotômica entre natureza e cultura (ANDION, SERVA \& LÉVESQUE, 2006, p.206). Segundo esses autores:

A sustentabilidade territorial decorre de um processo de "construção social' em contextos socio-espaciais e temporais específicos, nos quais princípios e normas gerais são reinterpretados pelos atores locais. Esses atores constroem respostas que podem ser mais ou menos adaptadas às problemáticas colocadas pela crise socioambiental nos níveis global e local. O desafio é então o de analisar essas respostas e a sua capacidade de fazer frente a tais problemáticas de forma inovadora.

Nesse sentido, a esfera municipal torna-se um palco privilegiado de experimentação de novas tecnologias sociais e formas institucionais que possam contribuir para a construção de formas de desenvolvimento mais sustentáveis. Porém, para que isso ocorra, é necessário que alguns aspectos sejam levados em conta na gestão e no planejamento municipais, o que será abordado a seguir.

\section{Possibilidades objetivas de aplicação da aborda- gem do DTS na gestão municipal}

Como fazer do espaço municipal um lócus favorável a dinâmicas de DTS, levando em conta o déficit institucional e os limites da municipalização abordados acima? Sem dúvida, como demonstra Vieira (2006), a implantação efetiva de um sistema integrado de gestão do DTS ainda está longe de ser uma realidade no caso da administração pública brasileira. Para que isso ocorra, segundo o autor citado, vários obstáculos, além dos já evidenciados neste texto, precisariam ser confrontados, tais como: (1) a disputa entre interesses contraditórios no seio do Estado que se reflete em prioridades e estratégias desconexas colocadas em prática pelos diferentes níveis governamentais em termos de desenvolvimento e gestão ambiental; (2) a ausência de controle social na formulação e na implementação 
das políticas ambientais; (3) a forte desigualdade na distribuição dos custos socioambientais dos projetos de desenvolvimento; (4) a falta de instrumentos eficazes de fiscalização e regulação socioambiental, além de capacitação técnica especializada por parte dos agentes públicos que atuam na esfera do desenvolvimento; (5) a ausência de uma abordagem preventiva, fazendo com que os problemas socioambientais sejam introduzidos na agenda governamental apenas por pressão, principalmente da mídia.

Para superar todos esses entraves torna-se necessário ir além de uma mudança técnico-administrativa na gestão municipal. É necessário promover uma verdadeira transformação no planejamento e na gestão pública em nível local, superando a dicotomia clássica entre centralização/descentralização. Neste sentido, o enfoque territorial apresenta-se como uma alternativa viável para consideração da relação entre o local e a dinâmica global, como explorado acima. Essa abordagem coloca-se como um contraponto às respostas neoliberais para enfrentamento da crise do fordismo, mostrando que os espaços locais não têm como destino apenas espelhar os movimentos globais. Trata-se de uma teoria do desenvolvimento "de baixo para cima", onde as comunidades locais mobilizam-se e articulam-se entre si para valorizar suas especificidades, frente a um processo de globalização crescente. Desse modo, as análises empíricas sobre as micro-iniciativas territoriais são valorizadas, em detrimento das "macro-teorias" explicativas. Tais abordagens abrem então espaço para que se leve em conta não apenas os resultados, mas também os processos de desenvolvimento, quer dizer, o modo como os atores estabelecem respostas particulares para diminuir a exclusão e as desigualdades sociais no meio em que vivem.

Porém, torna-se necessário ir além, inserindo a dimensão da sustentabilidade no enfoque territorial. Isso implica transpor a concepção meramente economicista do território que o interpreta como mero estoque de recursos que devem ser "otimizados", visando gerar vantagens competitivas. Como afirmam Vieira, Cazella e Cerdan (2006, p.15), a perspectiva do Desenvolvimento Territorial Sustentável "não se limita à busca de otimização dos fatores de produção para o crescimento econômico". Neste caso, os diferentes recursos (materiais e simbólicos) de um território não são apenas 
fontes de vantagens comparativas, mas "passam a ser vistos como expressão de um patrimônio natural e cultural compartilhado pelas populações" e que por isso precisam ser geridos e utilizados com prudência ecológica. Segundo os autores, "o conceito de recurso patrimonial (grifo nosso) permite que se aprofunde a reflexão sobre a sustentabilidade ecológica, social e política das dinâmicas territoriais de desenvolvimento".

A abordagem do DTS abre assim novas perspectivas analíticas e metodológicas em termos de gestão e planejamento público, trazendo à tona novos dispositivos institucionais que podem ser utilizados de modo a ampliar a efetividade da administração municipal. Dentre eles destacam-se (WEBER, 2000; SACHS, 2004 e VIEIRA, 2006):

- Espaços de articulação (horizontais e verticais), de planejamento e de gestão pública do território, que ampliem a participação da sociedade civil na esfera pública e permitam a construção coletiva de respostas aos problemas de desenvolvimento prioritários no nível local, de forma criativa, valorizando a inscrição social, cultural e histórica dos processos de desenvolvimento;

- A análise e a consideração das especificidades e dos recursos patrimoniais (tanto naturais, como culturais) nos processos de desenvolvimento, por meio de avaliações de ecossistemas e paisagens e dos usos dos recursos de uso comum (VIEIRA, BERKES e SEIXAS, 2005) como paisagem, sítios arqueológicos, florestas, águas, atmosfera, fauna, biodiversidade, entre outros (VIEIRA, 2006). Desse modo, pode-se efetuar não apenas a "ativação" desses recursos como defendido por Pequeur e Colletis (1993), mas a sua gestão prudente em termos ecológicos, com vistas a preservar o direito das gerações futuras de usufruí-los;

- A concepção e implementação de novos dispositivos de gestão de conflitos, de contratualização, de regulação e de fiscalização ambiental, baseados na participação comunitária e em outras formas de controle (estatais e via mercado) que possam constituir sistemas de gestão integrados de recursos de uso comum (VIEIRA, 2006).

- A criação de uma legislação ambiental mais compatível à realidade territorial e à "gestão comunitária dos recursos de uso comum" 
(VIEIRA, 2006), além de mecanismos de incentivo que possam estimular a criação de tecnologias adaptadas e de práticas de gestão mais responsáveis em termos socioambientais

Todos esses mecanismos podem ajudar a ampliar os limites do desenvolvimento do município, inserindo-o numa perspectiva mais ampla que transcende a leitura meramente economicista de curto prazo e considera as questões de territorialidade e de sustentabilidade. Porém, a sua aplicação exige uma mudança mais do que operacional e técnica e, principalmente, ético-política na esfera da gestão municipal.

\section{Considerações finais}

Buscamos mostrar neste texto as possibilidades de aplicação da abordagem do Desenvolvimento Territorial Sustentável no âmbito da administração municipal no Brasil. Para tanto, iniciamos mostrando que o processo de descentralização com base nos municípios tem sua origem nos primórdios da administração pública brasileira. Esse processo sofre uma institucionalização e um reforço exponencial a partir da Constituição de 1988, quando ocorre um novo pacto federativo e os municípios tornam-se entes autônomos em termos legais e administrativos em relação às outras esferas governamentais. Mostramos que, apesar de representar importantes avanços em termos de descentralização das políticas, a municipalização não resultou em mudanças significativas em termos de diminuição das desigualdades intraregionais ou de ampliação da efetividade das políticas públicas voltadas para a promoção do desenvolvimento regional.

Vários são os limites para que os municípios sejam lócus efetivos de promoção do Desenvolvimento Territorial Sustentável, especialmente se consideramos a realidade de $80 \%$ dos 5564 municípios brasileiros que estão nas áreas rurais. A maioria deles não possui receita monetária própria e é fortemente dependente dos repasses dos estados e do governo federal. Por isso, encontram diversos obstáculos estruturais e institucionais para o desempenho de seu papel enquanto agentes de políticas públicas. Os conselhos municipais, por sua vez, na sua maioria carecem de representatividade; seus membros não possuem qualificação e formação devida 
e não dispõem dos meios administrativos e financeiros para agir de forma mais pró-ativa no controle social das políticas. Somase a estes aspectos o evidente déficit de aplicação da legislação, além da falência dos dispositivos de regulação e de fiscalização no campo ambiental. Tudo isso faz com que a maioria dos municípios tenha um papel pouco relevante na mudança nas regras do jogo em termos de definição de prioridades, estratégias e mecanismos de desenvolvimento adotados nas diferentes regiões do país.

Diante desse quadro, fica evidente que uma mudança no papel das administrações municipais na definição dos rumos em termos de desenvolvimento exige transformações não apenas na esfera da gestão. Não basta capacitar os gestores municipais para que eles atuem como Chief Executive Officers (CEOs) nas prefeituras. Torna-se necessário pensar em novos arranjos institucionais que possam estimular não apenas a descentralização, mas também a coordenação entre as diferentes iniciativas municipais, tendo como foco a gestão integrada dos recursos de uso comum do território. Neste sentido, a abordagem do Desenvolvimento Territorial Sustentável - que enfatiza a valorização dos recursos patrimoniais do território, por meio da articulação negociada entre atores da esfera pública e privada, com vistas à promoção de novos estilos de desenvolvimento - pode apresentar importantes pistas para superar alguns dos principais limites da municipalização.

Recebido em 2.2.2009

Aprovado em 10.4.2009

\section{Referências}

ANDION, C. Atuação das ONGs nas Dinâmicas de Desenvolvimento Territorial Sustentável no meio rural de Santa Catarina. Os casos da APACO, do Centro Vianei de Educação Popular e da Agreco. Tese de Doutorado. Programa Interdisciplinar em Ciências Humanas. Florianópolis: UFSC, 2007.

ANDION, C.; SERVA, M \& LÉVESQUE, B. O debate sobre economia plural e sua contribuição para o estudo das dinâmicas de desenvolvimento territorial sustentável. In: Eisforia. 4 (4), Florianópolis, 2006. 
AROCENA, J. L'avenir des régions et la problématique sociale. In: GUESNIER, B. \& JOYAL, A. (Eds.) Le développement territorial. Regards croisés et les stratégies. Poitiers : IERF, 2004.

ARRETCHE, M.T.S. Políticas Sociais no Brasil: descentralização em um Estado Federativo. In: Revista Brasileira de Ciências Sociais. 14 (40), p. 1-36, 1999.

BEDUSCHI FILHO L.C. \& ABRAMOVAY, R. Desafios para o desenvolvimento de regiões rurais. Nova Economia, 14 (3), 35-70, 2004.

BENKO, G ; LIPIETZ, A. (Dirs.) La richesse des régions. La nouvelle géographie socio-économique. Paris: Presses Universitaires de France, 2000.

BERKES, F.; COLDING, J. \& FOLKE, C. Navigating Social-Ecological Systems: building resilience for complexity and change. Cambridge: Cambridge University Press, 2003.

BERKES, F \& FOLKES, C. Linking social and ecological systems. Cambridge: Cambridge University Press, 1998.

BROSE, M. Descentralização e Good Governement: como aperfeiçoar o desempenho dos governos locais. In: Revista do Serviço Público, 53 (3), p. 93-133, 2002.

CAMARGO, A. Atualidade do federalismo: tendências internacionais e experiências estratégicas. In: VERGARA, S.C; ALMEIDA CORRÊA, V.L. (Org.). Propostas para uma Gestão Pública Efetiva. Rio de Janeiro: FGV, 2004.

CARRIÈRE, J.P. As bases teóricas das estratégias de desenvolvimento local sustentável. Material do Curso de Formação em Desenvolvimento Sustentável. Florianópolis: UFSC. Mimeo, 2004.

CARRIÈRE, J.P. Do espaço geográfico ao território de projeto: história de um conceito. Seminário proferido para o curso de administração de serviços públicos. Florianópolis : ESAG/UDESC. Mimeo, 2007.

CNPQ. O plano nacional de educação prevê a instalação de planos em todos os municípios. Brasília: CNPq, 2008.

COURLET, C. \& FERGUENE, A. Gouvernances et dynamiques territoriales : points de rèpere analytiques. In: Ferguène, A. (Ed.). Gouvernance locale et développement territorial : les cas du pays 
du sud. Actes du colloque internationale de Constantine.. Paris: L'Harmattan, 2004.

COSTA, F.L \& CUNHA, A.P.G. Pensar o desenvolvimento a partir do local: novo desafio para os gestores públicos. In: VERGARA, S. \& ALMEIDA CORRÊA, V.L. (Org.) Propostas para uma Gestão Pública Efetiva. Rio de Janeiro: FGV, 2004.

DaMATTA, R. A casa e a rua. Rio de Janeiro: Guanabara, 1991.

DEFFONTAINES, J.P.; MARCELPOIL, E. \& MOQUAY, P. Le développement territorial: une diversité d'interprétations. In: Lardon, S.; Maurel, P. \& Piveteau, V. (Eds.) Répresentations spatiales et développement territorial. Paris : Hèrmes Sciences Publications, 2001.

FARAH, M.F.S. Parcerias, novos arranjos institucionais e políticas públicas locais. In: Cadernos de Gestão Pública e Cidadania. Vol. 18, São Paulo: FGV, 2000.

FARAH, M.F.S. \& BARBOZA, H.B. Novas Experiências de Gestão Pública e Cidadania. Rio de Janeiro: FGV, 2001.

FAURÉ, I. (2005) Des politiques publiques descentralisées entraves au développement local: expériences bresiliennes. In: Revue Tiers Monde, Vol. 181.

FONTAN, J-M ; KLEIN J-L. \& LEVESQUE, B. (Eds.) Réconversion Économique et Développement Territorial. Quebec: Presses Universitaires du Québec, 2003.

GAETANI, F. O ensino da administração Pública em um momento de inflexão. Revista do Serviço Público. Ano 50; Número 4: OutDez, 1999.

GUERREIRO RAMOS, A. A Nova Ciência das Organizações. Rio de Janeiro: FGV, 1989.

GUMUCHIAN H.; GRASSEL E.; LAJARGE R. \& ROUX, E. Les acteurs ces oubliés du territoire. Paris: Anthropos, 2003.

HOLLING, C; BERKES, F \& FOLKES, C. Ciência, sustentabilidade e gestão de recursos. In: BERKES, F. \& FOLKES, C. Linking Social and ecological systems. Cambridge: Cambridge University Press, 1998.

JOLLIVET, M. \& PAVÉ, A. O meio ambiente: questões e perspectivas para a pesquisa. In: VIEIRA, P.F. \& WEBER, J. Gestão de recursos 
renováveis e desenvolvimento: novos desafios para a pesquisa ambiental. São Paulo: Cortez, 1997.

MEADOWS, D. H. et. al. The limits to growth. New York, Potomac, 1972.

MELLO, D. L. (2001) Governo e administração municipal: a experiência brasileira. Revista de Administração Pública. 35 (2):79-96, mar-abr.

NAESS, A. (1990) Ecology, Community and Lifestyle: Outline of an Ecosophy. Cambridge: Cambridge University Press.

NUNES, E. O. A Gramática Política do Brasil. Rio de Janeiro: Zahar, 1994.

PEARCE, D.; MARKANDYA, A. \& BARBIER, E. B. Blueprint for a Green Economy. Londres: Earthscan Publication, 1989.

PECQUEUR, B. Le developpement territorial: une nouvelle approche des processus de développement pour les économies du Sud. In: Antheaume, B \& Giraut, F. (Eds.) Le territoire est mort. Vive les territoires. Paris: IRD, 2005.

PECQUEUR, B. Le tounant territorial de l'économie globale. Espaces et Sociétés. (124-125) 2-3, 17-32, 2006.

PECQUEUR B. \& COLLETIS G. Intégration des espaces et quasi intégration des firmes: vers de nouvelles rencontres productives ? In: Revue d'Économie Régionale et Urbaine, n³3, pp.489-508, 1993.

PEZZEY, J. Economic Analysis of Sustainable Growth and Sustainable Developement. World Bank, Environment Departement. Working Paper $\mathrm{n}^{\mathrm{O}}$ 15: Washington, 1989.

PNUMA; IBAMA; UMA . Perspectivas do meio ambiente mundial. GEO 3,2004.

POCHMANN, M. \& AMORIM, R. Atlas da exclusão social no Brasil. São Paulo: Cortez, 2003.

ROSSI, P. (1998) Attengiamenti dell'uomo verso la natura. In: CERUTI, M. e LAZLO, E. Physis: abitare a terra. Milão: Feltrinelli, 1988: 204. Tradução por Selvino J. Assmann.

SACHS, I . Stratégies de l'écodéveloppement. Paris: Les editions ouvrières, 1980. 
. Espaços, Tempos e Estratégias de Desenvolvimento. São Paulo: Vértice, 1986.

. L'écodéveloppement: stratégies pour le XXI ${ }^{\mathrm{eme}}$ siècle. Paris: Syros, 1997.

. Caminhos para o Desenvolvimento Sustentável. Rio de Janeiro. Garamond, 2000.

. Desenvolvimento includente, sustentável e sustentado. Rio de Janeiro: Garamond, 2004.

TOMIO, F.R. de L. A criação de municípios após a constituição de 1988 In: Revista Brasileira de Ciências Sociais. 17 (48), p. 61-226, 2002.

VAILLANCOURT, J.G. Sociology of the environment : from human ecology to ecossociology. In: MEHTA, M. D. \& OUELLET, E. (Eds.) Environmental Sociology. Theory and practice. North York: Captus Press, 1995.

VERGARA, S.C \& ALMEIDA CORRÊA, V.L. (Org.) Propostas para uma Gestão Pública Efetiva. Rio de Janeiro: FGV, 2004.

VIEIRA P.H.F. Meio-ambiente, desenvolvimento e planejamento. In: VIEIRA, P.H.F. et. al. Meio-ambiente, desenvolvimento e cidadania. São Paulo: Cortez, 2001.

. Rumo ao desenvolvimento territorial sustentável: esboço de roteiro metodológico participativo. In: Eisforia. 4 (4). Florianópolis, 2006.

VIEIRA, P. H. F.; CAZELLA, A.A. \& CERDAN, C. Introdução. In Eisforia. 4 (4). Florianópolis, 2006.

VIEIRA, P. H. F. \& TONNEAU, J.P. Que diretrizes de pesquisa para o desenvolvimento territorial no Brasil? In: Eisforia. 4 (4). Florianópolis, 2006.

WEBER, J. Gestão de recursos renováveis: fundamentos teóricos de um programa de pesquisas. In VIEIRA, P.H.F. \& WEBER, J. (Orgs.) Gestão dos recursos naturais renováveis e desenvolvimento. Novos desafios para a pesquisa ambiental. 2a Ed. São Paulo: Cortez, 2000. 


\begin{abstract}
Contributions to the debate on sustainable territorial development for effective municipal management

This article evaluates the possibilities for the application of the sustainable territorial development approach to the field of municipal management. Initially, our analysis deals with the historical and institutional context of municipal management in Brazil. We then proceed with an examination of the main advancements and limitations of the processes of federalization of municipalities after the promulgation of the 1988 Constitution. This in turn is meant to provide evidence of the main challenges that emerge around the engagement of local governments in promoting new styles of ecologically sustainable and socially inclusive development. From there, we move on to refine our concept of sustainable territorial development, through an incursion into the theoretical approaches on which the former is based. Finally, we seek to demonstrate the "objective possibilities" for applying this approach at the municipal level, particularly insofar as the conception and implementation of integrated and participatory plans for development are concerned.
\end{abstract}

Keywords: Sustainable territorial development, public policy, municipal management, ecologically sustainable development. 
